\title{
A Study of Changes in Various Echocardiographic Parameters in Patients with Chronic Stable Angina Undergoing Percutaneous Coronary Intervention (PCI)
}

\author{
MUHAMMAD MOBAROCK HOSSAIN, AKM FAZLUR RAHMAN, MD ABU SIDDIQUE, SAJAL KRISHNA \\ BANERJEE, CHOWDHURY MESKAT AHMED, HARISUL HOQUE, MOHAMMAD ABDUR RAHMAN, NOOR \\ MOHAMMAD, ARIFUL ISLAM JOARDER, FAKHRUL ISLAM KHALED, \\ MOHAMMAD FAISAL IBN KABIR, SYED ALI AHSAN
}

Department of cardiology, Bangabandhu Sheikh Mujib Medical University(BSMMU), Dhaka, Bangladesh

Address for Correspondence: Dr. Muhammad Mobarock Hossain, Resident, Department of cardiology, Bangabandhu Sheikh Mujib Medical University, Dhaka, Bangladesh, E mail: mobarockdr@gmail.com

\begin{abstract}
:
PCI has been used increasingly for revascularization in ischemic heart disease patients. In the cardiology practice, the assessment of left ventricular $(\mathrm{LV})$ function is of paramount importance. Two-dimensional echocardiography and Doppler echocardiography remain the most important diagnostic tests/tool for the evaluation of left ventricular function. The present study was conducted to determine the impact of PCI on myocardial function assessed by $2 \mathrm{D}, \mathrm{M}$ mode and tissue Doppler echocardiography in patients with chronic stable angina. The interventional study was carried out in the Department of Cardiology, University Cardiac Centre, Bangabandhu Sheikh Mujib Medical University Hospital, Dhaka over a period of 1 year between January 2013 to December 2013. Patients with chronic stable angina undergoing percutaneous coronary intervention (PCI) during the study period were the study population. A total of 40 such patients were consecutively included in the study. The myocardial function parameters were assessed by $2 D, M$ mode and Tissue Doppler echocardiography before PCI and 48 hours and 6 weeks after PCI. Left ventricular end diastolic dimension (LVEDD) did not experience any change 2 days after PCI, but a significant reduction was noted 6 weeks after PCI $(P<0.001)$. Similarly no change was observed 48 hours after PCI in left ventricular end systolic dimension (LVESD) but a significant decrease was evident 6 weeks after PCI $(p<0.001)$. LVEF also did not exhibit any change in the first 2 days after PCI, but significantly raised 6 weeks after PCI ( $p<$ 0.001). Tissue Doppler Imaging (TDI) showed that there was insignificant improvement in Em, Am, and Em/ Am ratio 48 hours after PCI. But there was significant improvement of the same parameters at the lateral mitral annulus 6 weeks after PCI ( $p=0.044, p=0.036$ and $p=0.021$ respectively). While DTm did not experience any change in first 2 days after PCI, it exhibited significant change at endpoint of study $(p=0.018)$, RTm and Sm peak velocity however, did not improve following PCI. Q-wave increased from $7.0 \mathrm{~cm} / \mathrm{sec}$ before PCI to $7.2 \mathrm{~cm} /$ sec 48 hours after PCI and $7.5 \mathrm{~cm} 6$ weeks after PCI $(p<0.001)$. Percentage of strain decreased from -15.0 before PCI to -15.4 at the endpoint ( $p<0.001$ ) and strain rate from -1.3\% before PCI to -1.4\% 6 at the endpoint. From the findings of the study it can be concluded that Tissue Doppler echocardiographic indices Strain, strain rate and $Q$ analysis can detect the early changes of improvement in the left ventricular myocardium in patient with chronic stable angina after 48 hours of PCI . Other 2D, M mode and tissue Doppler echocardiographic indices showed improvement after 6 weeks of PCI.
\end{abstract}

Introduction:

The basis of pathophysiologic benefit of revascularization is improving the function of viable myocardium ${ }^{37}$. Early coronary re-canalization helps to survive the viable myocardium and improve global LV function and survival ${ }^{46}$. According to the studies in patients with CAD and LV dysfunction, the disease outcome can be improved with surgical revascularization (CABG) or $\mathrm{PCI}^{37}$. PCI in patients with preserved LV function and optimal medical therapy doesn't reduce the cardiac death and MI, but it decreases the need for other procedure and the risk of angina. Its effect on LV systolic or diastolic function is not clear ${ }^{31}$. PCI has been used increasingly for revascularization in ischemic heart disease (IHD) patients. In most of the studies, the primary PCI, criterion such as ejection fraction (EF), diastolic function and the wall motion or chamber sizes has been investigated. But result of previous studies in related area, about elective PCI, has shown unequal viewpoints 1,6,13,27,30,32,39,41. Intervals between MI and PCI, basic left ventricular ejection fraction (LVEF) before PCI and global condition of the patients affect the result of PCI. Angina occurs when there is regional myocardial ischemia caused by inadequate coronary perfusion and is usually but not always induced by 
increases in myocardial oxygen requirements. Cardinal features of chronic stable angina include complete reversibility of the symptoms and repetitiveness of the anginal attacks over time, typically months to years. New, prolonged, or recent-onset symptoms are characteristic of unstable angina ${ }^{12}$. In chronic ischemia, myocardium is supposed to suffer and there is suppose to changes in myocardium eventually the left ventricular function ${ }^{51}$. In the cardiology practice the assessment of left ventricular (LV) function is of paramount importance. Clinical decisions regarding medical management, revascularization, and valve replacement often rely on its accurate assessment. They are very reliable in measuring the outcome of various cardiac and coronary procedures and also carry important prognostic indications.

Two-dimensional echocardiography and Doppler echocardiography remain the most important diagnostic tests/tool for the evaluation of left ventricular function. Compared with other imaging tests, echocardiography is portable, biologically safe, and cost-effective.Tissue Doppler echocardiography utilizes the modifications of blood flow by Doppler technology which calculates the velocity of myocardium segment by segment. This study aims to compare the various echocardiographic parameters and gives stimulus to formulate a echocardiographic guideline, which parameters to be practiced routinely and which parameters are needed at which period of time. This study will also strengthen or refute studies which have focused the newer parameters like myocardial function.

\section{Materials and Methods:}

Having obtained permission from the Ethical Committee of University Cardiac Centre, BSMMU, Dhaka, Bangladesh, this interventional study was carried out on patients with chronic stable angina undergoing percutaneous coronary intervention in the University Cardiac Centre, Department of Cardiology, BSMMU, Dhaka. After the selection of the patients in the study groups echocardiography of 2D, M mode and Tissue Doppler study were done. A variable frequency phasedarray transducer $(2 \cdot 5-3 \cdot 5-4 \cdot 0 \mathrm{MHz})$ was used for twodimensional, M-mode and Doppler imaging.Standard Doppler echocardiography was performed on the subjects in partial left decubitus position, by Vivid 7 Dimension.Doppler echocardiographic and tissue Doppler tracings were recorded on super VHS videotapes and high-fidelity paper strip at a velocity of 150 or $100 \mathrm{~mm} / \mathrm{s}$. All echo, Doppler and tissue Doppler measurements were analysed by two experienced readers using the recommendation of the American society of echocardiography by the average of five cardiac cycles, to minimize difference during the breath cycle. 2D and Mmode: Measurements of left ventricular walls and chambers were done according to the American Society of Echocardiography Measurements as follows: (A) Measurement of left ventricle: Left ventricular end diastolic diameter, Left ventricular end systolic diameter, Left ventricular ejection fraction (EF \%) \& Wall motion. (B)Tissue Doppler: In apical four-chamber view, the tissue Doppler sample volume was subsequently being placed at the level of left ventricular lateral mitral annulus. Tissue Doppler systolic indexes include: Myocardial peak velocity of Sm (m/s), Diastolic indexes included: Myocardial early (Em) and atrial (Am) peak velocities (m/s), Em/Am ratio, deceleration time (DTm) and relaxation time (RTm) (ms). Systolic and diastolic measurements may be determined in each regionas indexes of regional function. Myocardial functions were analyzed by: Tissue tracking or q-analysis, Strain \& Strain rate.

Data were processed and analysed using computer software SPSS (Statistical Package for Social Sciences) version 16 (SPSS Inc., Chicago, IL, USA).Continuous variables were expressed as means \pm SDs. Categorical variables expressed as frequency and corresponding percentages. To compare between the pre and post PCI groups the continuous variables were analyzed using the repeated measure ANOVA test. Multiple comparisons at different time intervals were done by General Linear Model Repeated Measures Define Factor(s). The level of significance was set at 0.05 and $\mathrm{p}<0.05$ was considered significant.

\section{Results:}

The present study intended to determine the impact of PCI on myocardial function in patients with chronic stable angina included a total of 40 patients. The myocardial function parameters were assessed by 2D, M mode and TissueDoppler echocardiography before PCI, 48 hours and 6 weeks after PCI. The findings of the study derived from data analyses are presented below:

Age distribution of the patients shows that 40-50 years age group comprised the main bulk (60\%) followed by < 40 years (20\%),50-60 years (15\%) and 60 or $>60$ years (5\%). The mean age of the patients was $46.4 \pm 6.5$ years and the minimum and maximum ages were 36 and 61 years 
respectively (Table I). Majority (95\%) of the patients were male giving a male to female ratio of 19:1 (Fig. 1). Fifty five percent of the patients were businessman, 30\% serviceholder and the rest 15\% were engaged in diverse occupation (Fig. 2). Over one-third (35\%) of the patients were of normal weight for their height, $60 \%$ overweight and 5\% obese (Fig. 3). Chest pain on exertion was the predominant complaint (95\%), followed by shortness of breath (85\%), fatigue (70\%) and palpitation (40\%). Ten percent patients had headache and 5 were asymptomatic (Fig. 4). Ninety percent of the patients had smoking habit diabetes, $15 \%$ diabetes, $70 \%$ family history of CAD and 35\% past history of associated illnesses (Fig. 5). Left ventricular end diastolic dimension (LVEDD) before PCI was $53.8 \mathrm{~mm}$ which did not experience any change 2 days after PCI, but a significant reduction was noted 6 weeks after PCI $(\mathrm{P}<0.001)$. Similarly no change was observed in left ventricular end systolic dimension (LVESD) between 24 hours before and 48 hours after PCI, but a significant decrease was evident 6 weeks after PCI $(\mathrm{p}<0.001)$. LVEF did not exhibit any change in the interval between 24 hours before and 48 hours after PCI, but significantly raised 6 weeks after PCI ( $<$ 0.001) (Table II, Table III and Fig 6-

Table-I

Distribution of the patients by their age $(n=40)$

\begin{tabular}{|c|c|c|}
\hline Age (years) $^{*}$ & Frequency & Percentage \\
\hline$<40$ & 20 & 20.0 \\
\hline $40-50$ & 24 & 60.0 \\
\hline $50-60$ & 6 & 15.0 \\
\hline$\geq 60$ & 2 & 5.0 \\
\hline
\end{tabular}

$*$ Mean age $=(46.4 \pm 6.5)$ years; range $=(36-61)$ years

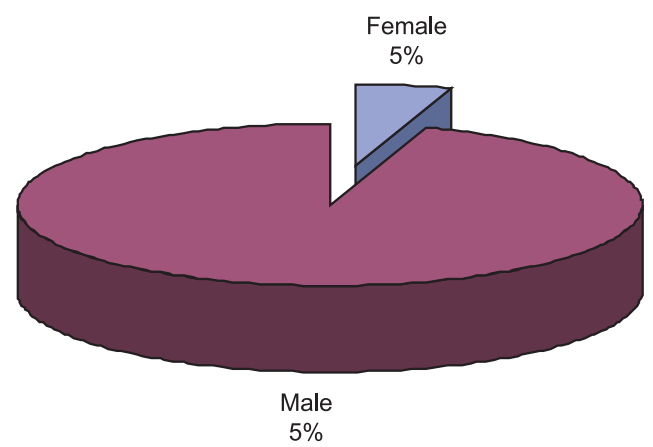

Fig.-1: Distribution of respondents by their sex $(n=40)$
8).Tissue Doppler Imaging (TDI) shows that there was insignificant improvement in Em, Am and Em/Am ratio 48 hours after PCI. But there was significant improvement of the same parameters at the lateral mitral annulus 6 weeks after PCI ( $p=0.044, p=0.036$ and $p=0.021$ respectively). While DTm did not experience any change 48 hours after PCI, it exhibited significant change 6 weeks after PCI ( $p=$ 0.018). But no change was noted during the interval between 24 hours before and 6 weeks after PCI in terms of RTm and Sm peak velocity (Table IV, Table V and Fig9-14). Q-wave increase from $7.0 \mathrm{~cm} / \mathrm{sec}$ before PCI to $7.2 \mathrm{~cm} / \mathrm{sec}$ 48 hours after PCI and $7.5 \mathrm{~cm} 6$ weeks after PCI $(\mathrm{p}<0.001)$. Percentage of strain decreased from -15.0 before PCI to 15.46 weeks after PCI $(\mathrm{p}<0.001)$ and strain rate from $-1.3 \%$ before PCI to $-1.4 \% 6$ weeks after PCI (Table VI, Table VII and Fig 15-17).

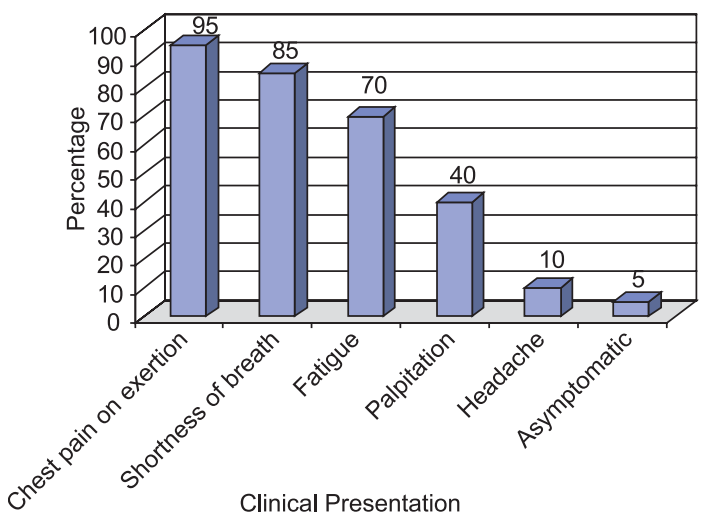

Fig.-2: Distribution of respondents by their clinical presentation $\left(n=40^{*}\right)$

*Total will not correspond to $100 \%$ for multiple responses

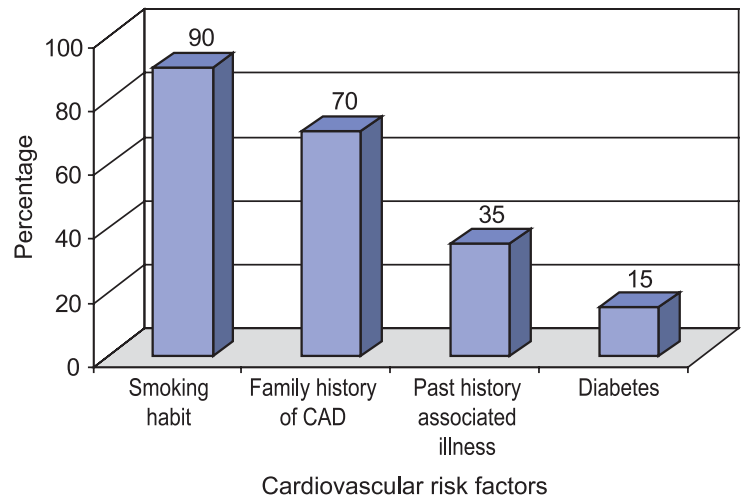

Fig.-3: Stratification of patients by their cardiovascular risk factors $\left(n=40^{*}\right)$

*Total will not correspond to 100 \% for multiple responses 
Table-II

Changes in LVsystolicfunction (2D \& M-mode) parameters

\begin{tabular}{lcccc}
\hline Left Ventriclular 2D TDI parameters & \multicolumn{3}{c}{ Evaluation time } & p-value \\
\cline { 2 - 4 } & 24 hrs before PCI & 48 hrsafterPCI & 6 wks after PCI & \\
\hline LVEDD $(\mathrm{mm})$ & $53.8 \pm 6.8$ & $53.3 \pm 5.9$ & $51.2 \pm 5.6$ & $<0.001$ \\
LVESD $(\mathrm{mm})$ & $35.7 \pm 5.8$ & $35.3 \pm 5.5$ & $33.7 \pm 5.4$ & $<0.001$ \\
LVEF $(\%)$ & $54.3 \pm 5.8$ & $54.6 \pm 5.2$ & $56.2 \pm 4.7$ & $<0.001$ \\
\hline
\end{tabular}

Table-III

Multiple comparisons at different time intervals of Left Ventriclular 2D \& M-mode

\begin{tabular}{llcc}
\hline Variables & Comparison between & Mean difference & p-value \\
\hline LVEDD(mm) & 24 hrs before PCI vs. 48 hrs after PCI & 0.450 & 0.381 \\
& 48 hrs after PCI vs. 6 weeks after PCI & 2.100 & $<0.001$ \\
& 24 hrs before PCI vs. 6 weeks after PCI & 2.550 & $<0.001$ \\
LVESD $(\mathrm{mm})$ & 24 hrs before PCI vs. 48 hrs after PCI & 0.300 & 0.209 \\
& 48 hrs after PCI vs. 6 weeks after PCI & 1.700 & $<0.001$ \\
& 24 hrs before PCI vs. 6 weeks after PCI & 2.000 & $<0.001$ \\
LVEF $(\mathrm{mm})$ & 24 hrs before PCI vs. 48 hrs after PCI & 0.350 & 0.480 \\
& 48 hrs after PCI vs. 6 weeks after PCI & 1.600 & $<0.001$ \\
& 24 hrs before PCI vs. 6 weeks after PCI & 1.950 & $<0.001$ \\
\hline
\end{tabular}

.Table-IV

Changes echocardiographic parameters at the lateral mitral annulus

\begin{tabular}{lcccc}
\hline LV lateral annulus & \multicolumn{3}{c}{ Evaluation time } & p-value \\
\cline { 2 - 4 } & 24 hrsbefore PCI & 48 hrs after PCI & 6 wksafter PCI \\
\hline Em peak velocity (cm/s) & $34.7 \pm 20.1$ & $34.7 \pm 22.0$ & $34.8 \pm 23.4$ & 0.044 \\
Am peak velocity (cm/s) & $24.4 \pm 10.1$ & $24.4 \pm 10.1$ & $27.9 \pm 11.2$ & 0.036 \\
Peak Em/Am ratio & $1.480 \pm 0.510$ & $1.480 \pm 0.500$ & $1.471 \pm 0.511$ & 0.021 \\
DTm (ms) & $137.1 \pm 22.0$ & $137.1 \pm 22.0$ & $137.3 \pm 22.0$ & 0.018 \\
RTm(ms) & $46.0 \pm 9.7$ & $46.1 \pm 9.7$ & $46.7 \pm 9.7$ & 0.761 \\
Sm peak (m/s) & $0.10 \pm 0.01$ & $0.11 \pm 0.01$ & $0.12 \pm 0.01$ & 0.830 \\
\hline
\end{tabular}


Table-V

Multiple comparison at different time intervals of LV lateral mitral annulus

\begin{tabular}{llcc}
\hline Variables & Comparison between & Mean difference & p-value \\
\hline Em peak velocity (cm/s) & 24 hrs before PCI vs. 48 hrs after PCI & 0.000 & 0.874 \\
& 48 hrs after PCI vs. 6 weeks after PCI & 0.100 & 0.013 \\
& 24 hrs before PCI vs. 6 weeks after PCI & 0.100 & 0.013 \\
Am peak velocity (cm/s) & 24 hrs before PCI vs. 48 hrs after PCI & 0.000 & 0.972 \\
& 48 hrs after PCI vs. 6 weeks after PCI & 3.600 & 0.040 \\
& 24 hrs before PCI vs. 6 weeks after PCI & 3.600 & 0.040 \\
Peak Em/Am ratio & 24 hrs before PCI vs. 48 hrs after PCI & 0.000 & 0.743 \\
& 48 hrs after PCI vs. 6 weeks after PCI & 0.009 & 0.048 \\
& 24 hrs before PCI vs. 6 weeks after PCI & 0.009 & 0.048 \\
DTm(ms) & 24 hrs before PCI vs. 48 hrs after PCI & 0.000 & 0.861 \\
& 48 hrs after PCI vs. 6 weeks after PCI & 0.150 & 0.037 \\
RTm(ms) & 24 hrs before PCI vs. 6 weeks after PCI & 0.150 & 0.037 \\
& 24 hrs before PCI vs. 48 hrs after PCI & 0.100 & 0.572 \\
Sm peak (m/s) & 48 hrs after PCI vs. 6 weeks after PCI & 0.600 & 0.649 \\
& 24 hrs before PCI vs. 6 weeks after PCI & 0.700 & 0.721
\end{tabular}

\section{Table-VI}

Changes in myocardial function following PCI

\begin{tabular}{lcccc}
\hline Myocardial function & \multicolumn{3}{c}{ Evaluation time } & \multicolumn{2}{c}{ p-value } \\
\cline { 2 - 4 } & 24 hrs before PCI & 48 hrs after PCI & 6 wks after PCI & $<0.001$ \\
\hline Q wave (cm/sec) & $7.00 \pm 1.20$ & $7.28 \pm 1.60$ & $7.56 \pm 1.51$ & $<0.001$ \\
Strain (\%) & $-15.0 \pm 1.7$ & $-15.1 \pm 1.7$ & $-15.4 \pm 1.7$ & $<0.001$ \\
Strain rate (\%) & $-1.3 \pm 0.1$ & $-1.4 \pm 0.1$ & $-1.4 \pm 0.1$ & \\
\hline
\end{tabular}

Table-VII

Multiple comparisons at different time intervals of Myocardial function by tissue Doppler

\begin{tabular}{llcc}
\hline Variables & Comparison between & Mean difference & p-value \\
\hline Q wave (cm/sec) & 24 hrs before PCI vs. 48 hrs after PCI & 0.276 & 0.002 \\
& 48 hrs after PCI vs. 6 weeks after PCI & 0.285 & $<0.001$ \\
& 24 hrs before PCI vs. 6 weeks after PCI & 0.561 & $<0.001$ \\
Strain (\%) & 24 hrs before PCI vs. 48 hrs after PCI & 0.109 & 0.006 \\
& 48 hrs after PCI vs. 6 weeks after PCI & 0.295 & $<0.001$ \\
& 24 hrs before PCI vs. 6 weeks after PCI & 0.404 & $<0.001$ \\
Strain rate (\%) & 24 hrs before PCI vs. 48 hrs after PCI & 0.039 & 0.105 \\
& 48 hrs after PCI vs. 6 weeks after PCI & 0.064 & $<0.001$ \\
& 24 hrs before PCI vs. 6 weeks after PCI & 0.103 & $<0.001$ \\
\hline
\end{tabular}




\section{Discussion:}

The present study was aimed at determining the impact of percutaneous coronary intervention (PCI) on myocardial function assessed by tissue Doppler echocardiography, and our target also was to find out if after PCI longitudinal and circumferential myocardial impairment improved or not. The potential of tissue Doppler-derived Measurements TDI is a promising technique in the evaluation and follow up of patients with ischemic heart disease. Myocardial hibernation represents chronically impaired myocardial function, which is fully reversible upon reperfusion ${ }^{20}$. There was significant improvement in E-wave, A-wave and E/A ratio at the lateral mitral annulus 6 weeks after PCI ( $\mathrm{p}=$ $0.044, p=0.036$ and $p=0.021$ respectively). The deceleration time (DTm) also exhibited significant change 6 weeks after PCI ( $p=0.018)$ which is consistent with Diller, et al's (2009) study. They examined twenty-four consecutive patients with chronic stable angina and preserved systolic left ventricular function who underwent PCI; patients had PW-TDI and conventional echocardiography before PCI, 1day, and 6 weeks after PCI. The results of their study showed that the systolic peak velocity improved in the septal, lateral, inferior, and right ventricular areas ( $p<0.05$ for each), but insignificant trend toward an improvement in the posterior wall ( $p=0.06)$ was found ${ }^{17}$. Consistent with findings in the present study Rashid (2012) showed that there was highly significant increase in systolic myocardial velocity $\mathrm{S}$ wave at inferior, anterior, septal, and lateral walls of LV, and also lateral wall of RV at 1 day, and 6 weeks after intervention, while it was insignificant at posterior wall of LV.

In the present study there was significant increase in LVEDD and LVESD with consequent improvement LVEF after intervention. Diller, et al. (2009) showed that the early diastolic velocities improved at all sites ( $\mathrm{p}<.05$ for each). The most pronounced improvement occurred in the septal area $^{17}$. In this present study, results are in agreement with Hashemi et al. (2010) They studied thirty patients who had single vessel disease (LAD disease), and underwent elective PCI providing that their systolic ejection fraction was $>40 \%$. All patients had pulsed wave TDI performed before PCI and 48 hours and 3 months after PCI; their study showed significant increase of early diastolic E' wave of the septal angle of mitral valve annulus ( $\mathrm{P}$ value $<0.05)^{25}$. In our study there was a significant increase of E'/A' ratio at the lateral angle of mitral valve annulus after PCI ( $p<0.05$. In Rashid et al's study there was a significant increase of E'/A' ratio at the lateral angle of mitral valve annulus after PCI ( $\mathrm{p}<0.05)$, but there was insignificant correlation between E'/A' ratio at lateral angle of tricuspid valve annulus before and after PCI, but our study did not include this parameter. Hashemi, et al. (2010) showed significant increase of E/A ratio of septal angle of mitral valve annulus after PCI (P value $<0.05$ ) (Hashemi et al. 2010), this is because they selected only the patients with LAD disease.

In the present study there were significant differences in all conventional echocardiographic measures (LVEDD, LVESD and LVEF) between baseline and 6 weeks following PCI. Diller and associates showed that trans-mitral and trans-tricuspid flow Doppler parameters and ejection fraction failed to reflect any improvement 1 day after PCI and 6 weeks after PCI ${ }^{17}$. In Rashid's study there was an insignificant relation among all conventional echocardiographic measures from baseline to 6 weeks after intervention, although similar agreement was lacking in study done by Carluccio et al. (2006), who reported that left ventricular volumes and contractile dysfunction as assessed by conventional echocardiography improved 8 \pm 3 months after revascularization in patients with impaired left ventricular function. This is the difference between our study and the study done by Carluccio et al. because we selected the patients with preserved systolic function, and may be due to short period follow up in our patients (6 weeks).

\section{Conclusion \& Recommendation:}

From the findings of the study it can be concluded that Tissue Doppler echocardiographic indices Strain, strain rate and Q analysis can detect the early changes of improvement in the left ventricular myocardium in patient with chronic stable angina after 48 hours of PCI . Other 2D , M mode and tissue Doppler echocardiographic indices showed improvement after 6 weeks of PCI .This small scale study may play a pivotal role in making a more conclusive large scale study.

\section{References:}

1. Agirbasli M, Guler N. 'Recovery of left ventricular systolic function after left anterior descending coronary artery stenting', J Interv Cardiol, 2005; 18(2): 83-8.

2. Bach DS, Armstrong WF, Donovan CL, Muller DWM. 'Quantitative Doppler tissue imaging for assessment of regional myocardial velocities during transient ischemia and reperfusion', Am Heart J, 1996; 132: 721-25.

3. Banerjee $P$, Card D. 'Preserving left ventricular function during percutaneous coronary intervention', J Invasive Cardiol, 2007; 19(10): 440-3.

4. Brun P, Tribouilloy C, Duval AM, Iserin L, Meguira A, Pelle G, Dubois-Rande JL. 'Left ventricular flow propagation during early filling is related to wall relaxation: a color M-mode Doppler analysis', J Am Coll Cardiol, 1992; 20: 420-32.

5. Bucher HC, Hengstler P, Schindler C, Guyatt GH. 'Percutaneous transluminal coronary angioplasty versus medical treatment for non-acute coronary heart disease: meta- 
analysis of randomised controlled trials', Br Med J, 2000; 321, 73-77.

6. Buszman P, Szkobka I, Tendera Z. 'Early and late results of percutaneous revascularization in patients with ischemic cardiomyopathy and decreased left ventricular ejection fraction', Euro Intervent, 2005; 2: 186-92.

7. Buszman P, Szkróbka I, Gruszka A, Parma R, Tendera Z, Leœko, Wilczyñski M, Bochenek T, Wojakowski W, Bochenek A, Tendera M. 'Comparison of effectiveness of coronary artery bypass grafting versus percutaneous coronary intervention in patients with ischemic cardiomyopathy', Am J Cardiol, 2007; 99(1): 36-41.

8. Carluccio E, Biagioli P, Alunni G, Murrone A, Giombolini C, Ragni T, Marino PN, Reboldi G, Ambrosio G. 'Patients with hibernating myocardium show altered left ventricular volumes and shape, which revert after revascularization: Evidence that dyssynergy might directly induce cardiac remodeling', J Am Coll Cardiol, 2006; 47(5): 969-77.

9. Çayly Murat, Usal Ayhan, Demir Mesut, Mehmet Kanadapý. 'The effect of successful elective percutaneous coronary intervention on left ventricular functions assessed with tissue Doppler imaging method', Türk Giripimsel Kard Der, 2007; 11: $146-50$.

10. Centurion OA. 'The open artery hypothesis: beneficial effects and longterm prognostic importance of patency of the infarctrelated coronary artery’, Angiology, 2007; 58: 34-44.

11. Chung CM, Nakamura S, Tanaka K, Tanigawa J, Kitano K, Akiyama T. 'Effect of recanalization of chronic total occlusions on global and regional left ventricular function in patients with or without previous myocardial infarction', Catheter Cardiovasc Interv, 2003; 60: 368-74.

12. Chronic Stable Angina. 'Jonathan Abrams', M.D.N Engl J Med, 2005; 352: 2524- 33, DOI: 10.1056/NEJMcp042317.

13. Connolly, HM \& Oh, JK. Echocardiography. In: Libby P, Bonow RO, Mann DL, Zipes DP, editors.Braunwald's Heart Disease: A Textbook of Cardiovascular Medicin, 8th ed. St. Louis, Mo: WB Saunders, 2007; 227-326.

14. Curtis JP, Krumholz HM. 'Keeping the patient in view: defining the appropriateness of percutaneous coronary interventions', Circulation, 2004; 110: 3746-48.

15. Dawson JR, Gibson DG. 'Left ventricular filling and early diastolic function at rest and during angina in patients with coronary artery disease', Br Heart J, 1989; 61: 248-57.

16. Devereux RB. 'Left ventricular diastolic dysfunction: early diastolic relaxation and late diastolic compliance', J Am Coll Cardiol, 1989; 13: 337-39.

17. Diller GP, Wasan BS, Thoma SA. 'Evaluation of improved myocardial function in patients with chronic stable angina and apparent normal ventricular function - a tissue Doppler study before and after percutaneous coronary intervention', J Am Soc Echocardiogr, 2009; 22: 177-82.

18. Dudek D, Rzeszutko L, Turek P, Sorysz D, Dubiel JS. 'Clinical predictors of left ventricular function improvement after percutaneous coronary interventions in patients with ejection fraction below 45\%', Przegl Lek, 2001; 58: 75 -54.
19. Dzavik V, Carere RG, Mancini GB, Cohen EA, Catellier D, Anderson TE, Barbeau G, Lazzam C, Title LM, Berger PB, Labinaz M, Teo KK, Buller CE. 'Total Occlusion Study of Canada Investigators. Predictors of improvement in left ventricular function after percutaneous revascularization of occluded coronary arteries: a report from the Total Occlusion Study of Canada (TOSCA)', Am Heart J, 2001; 142: 301-08.

20. Ferrari R, Ferrari F, Benigno M. 'Hibernating myocardium: Its pathophysiology and clinical role’, Mol Cell Biochem, 1998; 186(1-2): 195-9.

21. Garcia MJ, Smedira NG, Greenberg NL, , Main M, Firstenberg MS, Odabashian J, Thomas JD. 'Color M-mode Doppler flow propagation velocity is a preload insensitive index of left ventricular relaxation: animal and human validation', $J$ Am Coll Cardiol, 2000; 35: 201-08.

22. Gasior Z, Drzewiecki J, Wita K, Jaklik A, Gorycki B, Kinasz L, Szczogiel J, Czerwiñski C. 'Left ventricular systolic function after PTCA - recent and late assessment by exercise echocardiography', Pol Arch Med Wewn, 1994; 92: 307-12.

23. Gaziano, JM, Manson,, JE, Ridker, PM, Libby, P, Bonow, RO, Mann, DL \& Zipes, DP. Primary and secondary prevention of coronary heart disease, In: Braunwald's Heart Disease: A Textbook of Cardiovascular Medicine, 8th ed. St. Louis, Mo: WB Saunders, 2007; 1119-45.

24. Hashemi SR, Motamedi M, Khani M, Hekmat M, Gachkar L, Rezaeefar A. 'Evaluation of the effect of elective percutaneous coronary intervention as a treatment method on the left ventricular diastolic dysfunction in patients with coronary artery disease', J Tehran Univ Heart Center, 2010; 5(4): 194-8.

25. Hiatt, WR, Cooke, JP, Rutherford, RB. Atherogenesis and the medical management of atherosclerosis, Vascular Surgery, 5th ed. Philadelphia, PA: WBSaunders Co., 2000; 1: 333-46.

26. Ho CY, Solomon SD. 'A clinician's guide to tissue Doppler imaging’, Circulation, 2006; 113: e396-398.

27. Ioannidis JP, Katritsis DG. 'Percutaneous coronary intervention for late reperfusion after myocardial infarction in stable patients', Am Heart J, 2007; 154(6): 1065-71.

28. Isaaz K. 'What are we actually measuring by Doppler tissue imaging?,' J Am Coll Cardiol, 2000; 36: 897-99.

29. Jenkins C, Bricknell K, Hanekom L, Marwick TH. 'Reproducibility and accuracy of cardiographic measurements of left ventricular parameters using real-time threedimensional echocardiography', J Am Coll Cardiol, 2004; 44: 878-86.

30. Labovitz AJ, Lewen MK, Kern M, Vandormael M, Deligonal U, Kennedy HL. 'Evaluation of left ventricular systolic and diastolic dysfunction during transient myocardial ischemia produced by angioplasty', J Am Coll Cardiol, 1987; 10: 748-55.

31. Lane, GE, Holmes, Jr, Libby, P, Bonow, RO, Mann, DL \& Zipes, DP. Braunwald's Heart Disease Primary percutaneous coronary intervention in the management of acute myocardial infarction, A Textbook of Cardiovascular Medicine, 8th ed. St. Louis, Mo: WB Saunders, 2007; 1301-11. 
32. Leung WH, Lau CP. 'Correlation of quantitative angiographic parameters with changes in left ventricular diastolic function after angioplasty of the left anterior descending coronary artery’, Am J Cardiol, 1991; 67: 1061-66.

33. Masuyama T, Kodama K, Nakatani S, Nanto S, Kitabatake A, Kamada T. 'Effects of changes in coronary stenosis on left ventricular diastolic filling assessed with pulsed Doppler echocardiography', J Am Coll Cardiol, 1988; 11: 744-51.

34. Momtahen M, Abdi S, Ojaghi Z, Javady-nejad Z. 'Global and Regional Left Ventricular Function Improvement Following Successful Percutaneous Coronary Intervention in Patients with Ischemic Left Ventricular Dysfunction', Arch Iranian Med, 2007; 10(3): 387-9.

35. Nechvatal L, Hlinomaz O, Groch L, Hornacek I, Sitar J, Orban M, Petrikovits E. 'Serial echocardiographic assessment of the left ventricular function after direct PCI', Kardiol Pol, 2003; 59(11): 397-401.

36. Okrainec K, Banerjee DK, Eisenberg MJ. 'Coronary artery disease in the developing world', Am Heart J, 2004; 148(1): 7-15.

37. Phillips HR, O’Connor CM, Rogers J. 'Revascularization for heart failure’, Am Heart J, 2007; 153(4): 65-73.

38. Rashid H, Moniem AA, Email S, Batran ME. 'Evaluation of Myocardial Function in Patients with Chronic Stable Angina and Apparent Normal Ventricular Function (Tissue Doppler Study Before and After PCI)', Heart mirror journal, 2012; 6(2): 141-47.

39. Remmelink M, Sjauw KD, Henriques JP. ‘Acute left ventricular dynamic effects of primary percutaneous coronary intervention from occlusion to reperfusion', J Am Coll Cardiol, 2009; 53(17): 1498-502.

40. Ricou F, Lerch R, Meier B, Rutishauser W. 'Abnormal left ventricular filling pattern in patients with single vessel coronary artery disease: effect of angioplasty', Cardiology, 1992; 80: 230-36.

41. Rihal CS, Raco DL, Gersh BJ, Yusuf S. 'Indications for coronary artery bypass surgery and percutaneous coronary intervention in chronic stable angina: review of the evidence and methodological considerations', Circulation, 2003; 108(20): 2439-45.

42. Rosamond W, Flegal K, Friday G, Furie K, Go A, Greenlund K, Haase N, Ho M, Howard V, Kissela B, Kittner S, Lloyd-Jones D, McDermott M, Meigs J, Moy C, Nichol G, O’Donnell CJ, Roger V, Rumsfeld J, Sorlie P, Steinberger J, Thom T, Wasserthiel-Smoller S, Hong Y 2007, 'Heart disease and stroke statistics - 2007 update: a report from the American Heart
Association Statistics Committee and Stroke Statistics Subcommittee', Circulation, 115, e69-171.

43. Sattarzadeh R, Maleki M, Jamalian A, Amirpour A, Firuzi A, Samiei N, Esmaeilzadeh M,Ghorbani A, Tavoosi A. 'Colour M-mode superiority in evaluation of improvement in myocardial performance indices following successful percutaneous coronary intervention (PCI)', Cardiovasc J Afr, 2010; 22: 182-5.

44. Schinkel AF, Poldermans D, Vanoverschelde JL, Elhendy A, Boersma E, Roelandt JR, et al. 'Incidence of recovery of contractile function following revascularization in patients with ischemic left ventricular dysfunction', Am J Cardiol, 2004; 93: 14-17.

45. Sedlis SP, Ramanathan KB, Morrison DA, Sethi G, Sacks J, Henderson W. 'Department of Veterans Affairs Cooperative Study 385, Angina With Extremely Serious Operative Mortality Evaluation (AWESOME) Investigators. Outcome of percutaneous coronary intervention versus coronary bypass grafting for patients with low left ventricular ejection fractions, unstable angina pectoris, and risk factors for adverse outcomes with bypass (the AWESOME Randomized Trial and Registry)', Am J ardiol, 2004; 94: 118-20.

46. Silva JC, Rochitte CE, Júnior JS, Tsutsui J, Andrade J, Martinez EE, Moffa PJ, Menegheti JC, Kalil-Filho R, Ramires JF, Nicolau J. 'Late coronary artery recanalization effects on left ventricular remodelling and contractility by magnetic resonance imaging', Eur Heart J, 2005; 26(1): 36-43.

47. Sutherland GR, Stewart MJ, Groundstroem KW, Moran CM, Fleming A, Guell-Peris FJ, Riemersma RA, Fenn LN, Fox KA, McDicken WN. 'Color Doppler myocardial imaging: a new technique for the assessment of myocardial function', J Am Soc Echocardiogr, 1994; 7: 441-58.

48. Tumuklu M, Kayikcioglu M, Aliyev E, Cinar CS, Soydan I. 'Evaluation of early alterations in transmitral diastolic flow and tissue Doppler findings of the Basal segments of both ventricles in early period after coronary angioplasty’, Anadolu Kardiyol Derg, 2003; 3: 16-23, AXVII-AXVIII.

49. Vasan RS, Larson MG, Benjamin EJ, Evans JC, Reiss CK, Levy D. 'Congestive heart failure in subjects with normal versus reduced left ventricular ejection fraction: prevalence and mortality in a population- based cohort', J Am Coll Cardiol, 1999; 33: 1948-55.

50. Wang J, Abraham TP, Korinek J, Urheim S, McMahon EM, Belohlavek M. 'Delayed onset of subendocardial diastolic thinning at rest identifies hypoperfused myocardium', Circulation, 2005; 111(22), 2943-50. 